\title{
PROPOSTA PARA CONSTRUÇÃO DE OBJETO DE APRENDIZAGEM COMO APOIO AO ENSINO DE ARTE
}

\author{
PROPUESTA PARA LA CONSTRUCCIÓN DE OBJETOS DE APRENDIZAJE \\ COMO APOYO A LA ENSEÑNANA DE ARTE
}

\section{PROPOSAL FOR CONSTRUCTION OF LEARNING OBJECT AS SUPPORT TO THE TEACHING OF ART}

\author{
Marcos AMÉRICO ${ }^{1}$ \\ Maria da Graça Mello MAGNONI ${ }^{2}$ \\ Fernando Chade DE GRANDE ${ }^{3}$ \\ Elizabeth Rossi DE GRANDE ${ }^{4}$
}

RESUMO: A abrangência da arte como linguagem instituída é capaz de servir aos mais diversos contextos, nos traz subsídios para a compreende-la como área de conhecimento, com códigos e saberes próprios que, ao estar inserida nos currículos escolares demanda que seja atualizada ao ambiente contemporâneo de educação, integrando-se aos suportes digitais como possíveis recursos de expressão e comunicação, redesenhando o ensino de arte de forma contemporânea a partir do uso da tecnologia em sala de aula. A pesquisa propõe a construção de um Objeto de Aprendizagem conceituado como qualquer recurso que possa ser utilizado como apoio no processo educacional e que oferece $o$ suporte digital necessário para $o$ desenvolvimento da sequência proposta na busca de uma aprendizagem multidisciplinar e atual para o Ensino Fundamental em Arte.

PALAVRAS-CHAVE: Objeto de aprendizagem. Abordagem triangular. Arte.

RESUMEN: El alcance del arte como lenguaje instituido y capaz de servir a los más diversos contextos, nos trae subsidios para comprenderla como área de conocimiento, con códigos y saberes propios que, al estar inserta en los currículos escolares, demanda que sea actualizada al ambiente contemporáneo de Que se integran a los soportes digitales como posibles recursos de expresión y comunicación, rediseñando la enseñanza de arte de forma contemporánea a partir del uso de la tecnología en el aula.

\footnotetext{
${ }^{1}$ Universidade Estadual Paulista (UNESP), Bauru - SP - Brasil. Professor Assistente Doutor do PPG Mídias e Tecnologias. E-mail: tuca@faac.unesp.br.

${ }^{2}$ Universidade Estadual Paulista (UNESP), Bauru - SP - Brasil. Professor Assistente Doutor do PPG Mídias e Tecnologias. Grupo de Pesquisa LECOTEC (Laboratório de Estudos de Comunicação, Tecnologia e Educação). E-mail: sofia@fc.unesp.br.

${ }^{3}$ Universidade Estadual Paulista (UNESP), Bauru - SP - Brasil. Professor Assistente Doutor do PPG Mídias e Tecnologias. Doutorando em Mídia e Pesquisador vinculado ao GENEM - Grupo de Estudos sobre a Nova Ecologia dos Meios da FAAC - Unesp/Bauru. E-mail: fchade75@gmail.com.

${ }^{4}$ Universidade Estadual Paulista (UNESP), Bauru - SP - Brasil. Professor Assistente Doutor do PPG Mídias e Tecnologias. Mestranda em Mídia e Tecnologia. Membro do grupo de pesquisa Lecotec. E-mail: betharte75@gmail.com.
} 
La investigación propone la construcción de un Objeto de Aprendizaje conceptuado como cualquier recurso que pueda ser utilizado como apoyo en el proceso educativo y que ofrece el soporte digital necesario para el desarrollo de la secuencia propuesta en la búsqueda de un aprendizaje multidisciplinario y actual para la Enseñanza Fundamental en Arte.

PALABRAS CLAVE: Objeto de aprendizaje. Enfoque triangular. Arte.

ABSTRACT: The comprehensiveness of art as a language instituted and capable of serving the most diverse contexts, brings us to understand it as an area of knowledge, with its own codes and knowledge, which, being inserted in the school curricula, demands that it be updated to the contemporary environment of Education, integrating digital media as possible resources for expression and communication, redesigning the teaching of art in a contemporary way from the use of technology in the classroom. The research proposes the construction of a Learning Object conceptualized as any resource that can be used as support in the educational process and that offers the necessary digital support for the development of the proposed sequence in the search of a multidisciplinary and current learning for the Elementary Education in Art.

KEYWORDS: Learning object. Triangular approach. Art.

\section{INTRODUÇÃO}

Há tempos o homem busca formas de registro para suas ideias, sentimentos, histórias ou assuntos utilizando-se de linguagens. Mas como concretizar o que nos é abstrato? Neste embate entre sentimento e ideia registra-se pela primeira vez, nas paredes de uma caverna, algo que ganhou um significado, existindo como forma, cores e como sentimento. A ideia transforma-se em símbolo e então inaugura-se um novo período. Nasce o ser simbólico.

Como ser simbólico, o homem sistematizou seu mundo interior e exterior criando diversos sistemas de linguagens e entre estas, a Arte. Organizando sons, movimentos, gestos, luzes, cores ou formas com alguma intenção e atribuindo significado a sua criação, transforma, poetiza em música, desenho, pintura, dança, teatro, escultura, vídeos, fotografias... O homem produz arte.

Segundo Martins, Arte é uma linguagem, e como tal, para que se possa ser lida, compreendida e produzida material é necessário que se conheça diferentes produções artísticas, aproprie-se de seus códigos, saiba operar com eles e conheça autores que também produziram neste sistema de representação. É na escola que esta linguagem é apresentada formalmente à criança e, ao garantir a apropriação significativa do

RIAEE - Revista Ibero-Americana de Estudos em Educação, Araraquara, v.12, n.4, p.2273-2291, out./dez. 2017. 
conhecimento em Arte, estamos ampliando seu mundo, repertoriando-a da História da Arte e da sua própria história (MARTINS, 2009).

Portanto entendemos que Arte deve ser tratada como área de conhecimento e pesquisa. E como qualquer área do conhecimento humano, no contexto escolar, deverá ter seus objetivos, conteúdos e saberes próprios, pois está inserida num conjunto de manifestações simbólicas de uma determinada cultura, é criação e inovação.

$\mathrm{O}$ ato criador estrutura e organiza o mundo. Como afirmam os PCNs (Parâmetros Curriculares Nacionais), documento oficial que norteia a organização curricular nas Escolas Públicas, "não existe ciência sem imaginação e nem arte sem conhecimento" (PCN, 1997, p.47). Todo produto artístico origina-se de uma época, emerge da história e expressa conflitos humanos, interpretados à sua época. Esta dimensão nos possibilita ressignificar e trazer a arte para o momento atual e inserindo-a no universo da criança. Dessa forma, a obra de arte se torna atemporal, possível de leituras e novos significados, já que está sujeita às interferências da história de vida e do contexto de cada um que a lê. Ainda de acordo com os parâmetros curriculares nacionais, Arte é um modo privilegiado de conhecimento e aproximação entre indivíduos de diversas culturas, favorecendo o conhecimento de semelhanças e diferenças, em planos que vão além do discurso verbal.

Considerando estas concepções o objetivo desta pesquisa é desenvolver uma proposta de objeto de aprendizagem que seja suporte para arte educadores aplicarem no ensino artes da educação básica. O modelo sustentará pelo menos dois pilares da proposta triangular do ensino da arte (apreciação da obra de arte e a sua contextualização histórica) sistematizada pela professora e pesquisadora Ana Mae Barbosa no final dos anos de 1980.

O presente texto relata os trabalhos de pesquisa voltados ao desenvolvimento de Objeto de Aprendizagem (O.A.), utilizando as tecnologias digitais e os recursos multimídias, como recursos voltados à concretização da proposta triangular no ensino de Arte na Educação Básica.

\section{A abordagem triangular}

Nos anos 90, a professora Ana Mae Barbosa sistematizou o Ensino e Aprendizagem da Arte ao conceber uma proposta para a construção do conhecimento em Artes, denominada Abordagem Triangular e fez com que o ensino de arte fosse 
reconhecido nacionalmente. Segundo a autora, a proposta consiste em delimitar três eixos de ações complementares para serem utilizadas pelo arte educador: a contextualização histórica, o fazer artístico e a apreciação artística. A intersecção dos três eixos favorece a construção do conhecimento em Arte, segundo a proposta.

A Arte como uma linguagem aguçadora dos sentidos, de acordo com Barbosa, deve ser experimentada, decodificada por meio da leitura de imagem e problematizada para o momento atual, resultando em identificação cultural e desenvolvimento individual. Nas palavras da autora, "Só um saber consciente e informado torna possível a aprendizagem em Arte". (BARBOSA, 2007, p.17). Desta forma, é pertinente pontuar que:

Por meio da Arte é possível desenvolver a percepção e a imaginação, aprender a realidade do meio ambiente, desenvolver a capacidade crítica, permitindo ao indivíduo analisar a realidade percebida e desenvolver a criatividade de maneira a mudar a realidade que foi analisada. (BARBOSA, 2007, p. 18)

Segundo Pimentel, o exercício da abordagem triangular no ensino da arte, "potencializa a vivência pessoal e/ou bagagem imagética do aluno, gerando maior capacidade cognitiva em quaisquer práticas do conhecimento" (PIMENTEL, 2010, p. 225). Para a efetivação deste exercício a autora destaca que:

Nas aulas de Arte, não basta apenas propor e desenvolver atividades; é preciso desenvolver o pensamento artístico, diversificando-as, contextualizando-as, motivando a curiosidade e a investigação, interligando Aulas de Arte pressupõem intrinsicamente o trabalho com o pensamento artístico. (PIMENTEL, 2010, p. 212)

A compreensão de pensamento sistematizado por Mae para o Ensino de Arte a partir da abordagem triangular, nos leva ao referencial que norteia seu trabalho, as bases da pedagogia freireana que também fazem parte da formação da autora, aluna de Paulo Freire. Alinhando o pensamento de Ana Mae Barbosa para a abordagem triangular com alguns dos muitos embasamentos teóricos de Freire podemos considerar algumas reflexões a partir do esquema:

Figura 1: Síntese das bases freireanas e da abordagem triangular. 


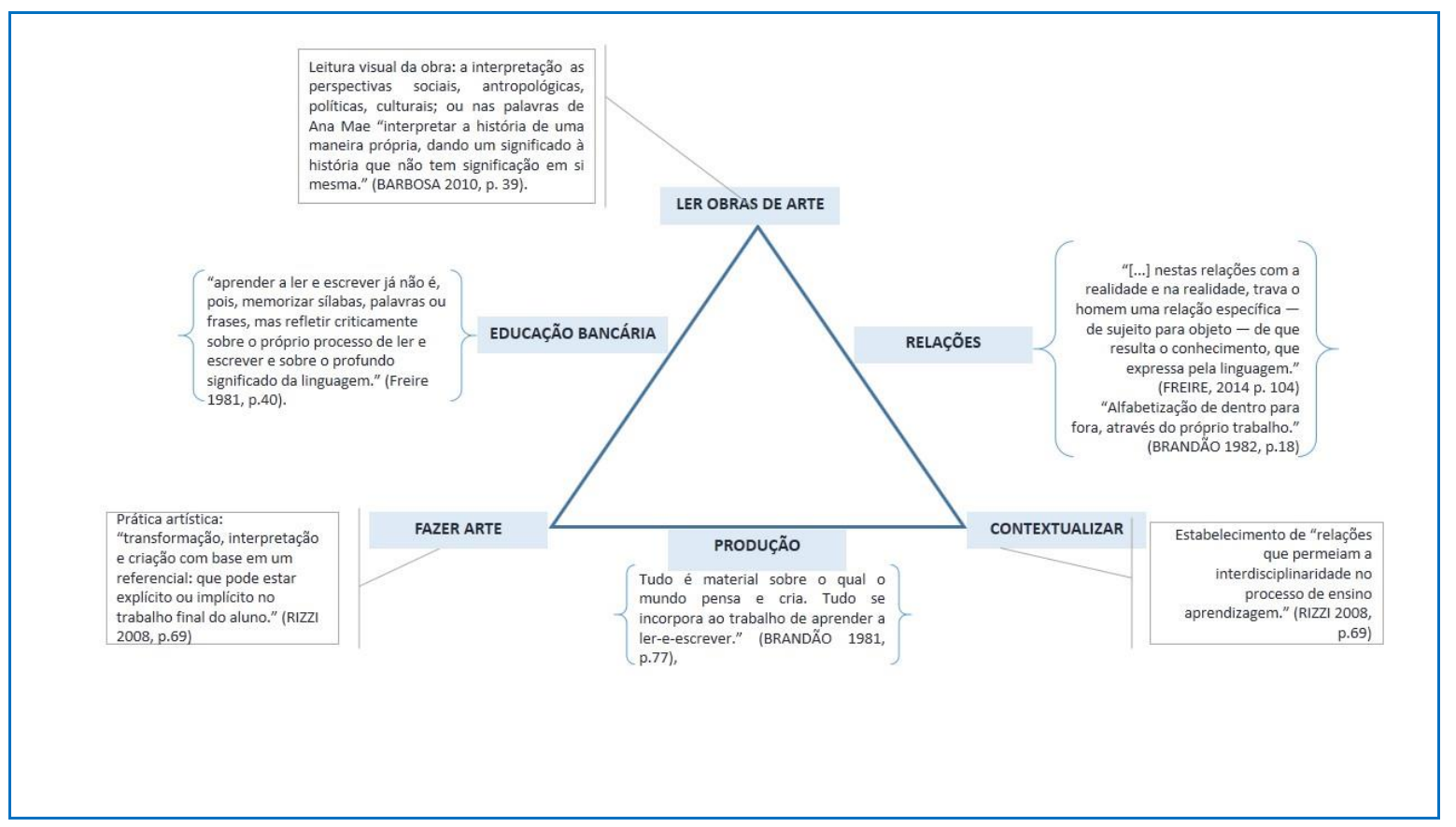

Fonte: Elaborada pelos autores.

O papel da Arte na escola é fundamental para a "alfabetização visual", para o processo de leitura de imagem e na significação que essa pode apresentar em diferentes contextos. Considerando a distribuição e consumo de imagens diárias a que somos submetidos pelas mídias através de ideias, produtos, conceitos ou comportamentos, a Arte na escola pode auxiliar, segundo Barbosa, "a exercitar a consciência acerca daquilo que aprendemos por meio da imagem.”. (BARBOSA, 2007, p.19)

Nesse sentido, a Abordagem Triangular trabalha a leitura de imagem a partir do eixo da apreciação artística, do contato com obras de arte que estimulem o reconhecimento e compreensão de códigos imagéticos e que alimentam o universo simbólico do aluno. Rizzi (2002) ressalta a importância de uma leitura crítica e estética para conseguir realizar uma boa leitura.

A leitura de obra de Arte envolve o questionamento, a busca, a descoberta da capacidade crítica dos alunos. As interpretações oriundas desse processo de leitura, relacionando sujeito/obra/contexto, não são passíveis da redução certo/errado. (RIZZI, 2002, p. 67)

\footnotetext{
${ }^{5}$ Para Barbosa (2010) o processo de alfabetização também se faz no campo visual e o ensino de arte contribui neste trabalho uma vez que as "artes plásticas também desenvolvem a discriminação visual, que é essencial ao processo de alfabetização. Para uma criança de seis anos as palavras lata e bola são muito semelhantes porque têm a mesma configuração gestáltica, isto é, uma letra alta, uma baixa, seguida de outra alta e mais uma baixa. Só uma visualidade ativa pode, nessa idade, diferenciar as duas palavras pelo seu aspecto visual, e esta capacidade de diferenciação visual é básica para a apreensão do código verbal que também é visual." (BARBOSA, 2010, p. 28)
} 
Pillar apresenta em seu artigo alguns dados de pesquisas sobre leitura de imagens realizada com crianças e estudiosos em Arte, que mostram a diversidade de significados quanto ao sentido que uma imagem ou obra de Arte podem gerar em cada criança, de acordo com a vivência e o contexto de cada leitor. A autora salienta que o processo de leitura de imagens em sala de aula com crianças não deve estar limitado apenas ao fascínio das cores, das formas e ritmos, mas ao entendimento dos processos de leitura por meio da problematização e reflexão de como os elementos visuais se estruturam para formar uma obra de arte (PILLAR, 2002).

Assim, a utilização de um Objeto de Aprendizagem (O.A.) como apoio aos professores de Arte reforçará as técnicas de leituras de imagem em sala de aula, além de complementar pesquisas em torno da contextualização das obras. As tecnologias digitais e as novas mídias podem ser suportes ao arte-educador quando, ao trabalhar a apreciação da obra e sua contextualização, tenha à sua disposição recursos multimídias que facilitem a elucidação da obra de arte aos alunos. Bertoletti (2011) afirma que "A diversidade de possibilidades que são oferecidas com as tecnologias digitais, em ensino e elaboração artística, devem ampliar o desenvolvimento crítico dos processos de ensino/aprendizagem da Arte". (BERTOLETTI, 2011, p. 6)

Essa mesma avaliação está em Portella que enfatiza a abordagem triangular vinculada a novas ferramentas tecnológicas ao abordar em sua pesquisa uma análise do Museu Virtual do Projeto Portinari que serviu de referência oferecida pelo Grupo de Trabalho Museus Virtuais da PUC-RJ (PORTELLA, 2002). A pesquisa teve como objetivo analisar o conteúdo do site e indicar as possibilidades de utilização no contexto educacional.

\footnotetext{
A internet é um instrumento poderoso de ação artístico-cultural, por sua inédita capacidade de levar imagens, textos e documentos hipermídia, possibilitando assim gerar novos paradigmas no âmbito das propostas do ensino de Arte. (PORTELLA, 2002, p. 124)
}

Para Pimentel, por meio do uso da tecnologia em Arte "a imagem ganha, a cada avanço tecnológico, mais e mais possibilidades de apropriação e ressignificação" (PIMENTEL, 2002, p. 115), entretanto, a autora orienta a necessidade do conhecimento em Arte, para que se possa determinar qual o melhor caminho na utilização dos recursos tecnológicos contemporâneos. "Ao se optar por usar um ou mais recursos tecnológicos, 
essa escolha deve justificar-se pela melhor adequação da expressão artística possibilitada por esse ou esses meios.” (PIMENTEL, 2002, p. 116)

\section{Objetos de aprendizagem}

O O.A. proposto nessa pesquisa pretende reunir em uma mesma plataforma digital as diversas referências que a internet disponibiliza sendo imagens, sons, vídeos, textos e informações que contextualizem e contribuam para a leitura de imagem de uma obra de arte, contribuindo dessa forma para o ensino aprendizagem em Arte.

A conceituação sobre objetos de aprendizagem encontra diferentes definições de acordo com as características que seus autores preferem enfatizar. Segundo Gutierrez (2004), um O.A. não precisa ser necessariamente um meio digital, mas qualquer recurso que seja usado como apoio ao aprendizado. (GUTIERREZ, 2004)

\footnotetext{
Um cartaz, uma maquete, uma canção, um ato teatral, uma apostila, um filme, um livro, um jornal, uma página na web, podem ser objetos de aprendizagem. A maioria destes objetos de aprendizagem pode ser reutilizada, modificada ou não e servir para outros objetivos que não os originais. (GUTIERREZ, 2004, p. 6)
}

A definição sustentada pelo IEEE (Institute of Electrical and Electronics Engineers) para Objetos de Aprendizagem é considerada abrangente por afirmar que “Objetos de aprendizagem podem ser definidos como qualquer entidade digital ou nãodigital, que pode ser usada, reusada ou referenciada durante a aprendizagem suportada pela tecnologia" (IEEE, 2003, p. 6). Wiley (2004) considera objetos de aprendizagem apenas os recursos digitais "qualquer recurso digital que pode ser reutilizado para apoiar a aprendizagem" (WILEY, 2004, p. 4), podendo, segundo o autor, ser imagens digitais, vídeos gravados ou ao vivo, dados, fragmentos de áudio, texto e animações nos mais diferentes formatos e combinações que podem também trafegar pela internet e serem reutilizados em diversas mídias digitais.

Nunes comenta que para armazenar os conteúdos digitais no Brasil, foram criados repositórios, ou seja, "bancos de dados que armazenam dados sobre os objetos, os metadados, e os objetos em si" (NUNES, 2004, p. 3). O autor estabelece restrição ao conceituar O.A. limitando-os aos recursos digitais que possuem "enfoque educacional" (NUNES, 2004). 
A preocupação com a definição das características de um O.A. pode ser observada na produção de Tarouco que defende a utilização dos metadados que funcionam para catalogar os O.A. em repositórios que poderão ser acessados por sistemas de busca e utilizados através do learning management systems (LMS) ${ }^{6}$. (TAROUCO, 2003)

Objetos educacionais são mais eficientemente aproveitados quando organizados em uma classificação de metadados e armazenados em um repositório integrável a um sistema de gerenciamento de aprendizagem (Learning Management System). (TAROUCO, 2003, p. 2)

De acordo com Vieira (2007), "os objetos de aprendizagem devem ser desenvolvidos de maneira a prover compatibilidade com outros objetos" (VIEIRA, 2007, p.2). Para isso, o autor acrescenta que é preciso haver uma padronização de parâmetros no desenvolvimento de O.A., previamente definidos por um conjunto de especificações entre as quais o autor destaca o Instructional Managment System (IMS) Learning Design, o Sharable Content Objetct Reference Model (SCORM) e o Aviation Industry CBT (Computer-Based Training) Committe (AICC) (VIEIRA, 2007).

O padrão $\mathrm{SCORM}^{7}$ é utilizado no desenvolvimento de diversos O.A. de maneira que seja um modelo de referência para produção de software e-learning ${ }^{8}$ podendo ser reutilizá-los em diversos contextos por sistemas adaptados a este mesmo padrão.

O SCORM (Sharable Content Object Reference Model) é um modelo de referência para construção de objetos de aprendizagem de modo que eles sejam reutilizáveis e interoperáveis para qualquer LMS, desde que suporte este modelo, isto é, padronizando uma maneira única de iniciar e comunicá-los com o LMS. (DA SILVA, 2008, p. 20)

Da Silva observa alguns requisitos para que um O.A. possa ser considerado um objeto no padrão SCORM (DA SILVA, 2008):

- Reusabilidade: podem ser alterados com facilidade e possibilidade de utilização em diversas plataformas e múltiplas aplicações;

- Acessibilidade: capacidade de tornar objetos educacionais acessíveis em qualquer local remoto podendo ser utilizados em diversos outros locais;

${ }^{6}$ Disponível em: https://en.wikipedia.org/wiki/Learning_management_system.

${ }^{7}$ Disponível em: http://www.adlnet.gov/scorm.html.

${ }^{8}$ Disponível em: https://pt.wikipedia.org/wiki/E-learning.

RIAEE - Revista Ibero-Americana de Estudos em Educação, Araraquara, v.12, n.4, p.2273-2291, out./dez. 2017. 
- Interoperabilidade: possibilidade de ser operável e funcional em diferentes locais e plataformas e em diferentes tipos de sistemas operacionais, hardwares e navegadores web;

- Durabilidade: os recursos educacionais disponibilizados devem perdurar mesmo que se mude a base tecnológica para novas versões de hardware, não necessitando realizar alterações significativas;

As mídias digitais permitem por meio da internet, que conteúdos de aprendizagem armazenados em repositórios sejam acessados para serem utilizados para fins educacionais. Os repositórios permitem que usuários de diferentes localidades acessem o O.A. partilhando dessa maneira a informação para muitas pessoas. Américo, apresenta uma proposta de produzir programas para TV Interativa em animação para o ensino de Ciências adaptando um objeto de aprendizagem desenvolvido para o projeto RIVED $^{9}$ (Rede Interativa Virtual de Educação) chamado "Calorímetro"10. A pesquisa adaptou os conteúdos de Objetos de Aprendizagem Web para TV Digital Interativa, ou seja, conforme as definições de Wiley (2004), reutilizando objetos de aprendizagem que já existiam na Web em outra mídia digital, no caso a TV Digital interativa. (AMÉRICO, 2010)

Sobre a utilização de O.A. como apoio ao ensino, na medida em que facilita a disponibilidade e acesso à informação no ciberespaço, Wiley (2004) salienta que que "se objetos de aprendizagem alcançarem o seu público e fornecerem a base para uma arquitetura de aprendizagem adaptável, geradora e escalável, o ensino e a aprendizagem que nós conhecemos serão revolucionados”. (2000, p. 29)

\section{Porque a arte é uma linguagem}

Para os Parâmetros Curriculares Nacionais para o Ensino de Arte, a obra de arte promove um encontro entre dois universos humanos e revela a possibilidades de comunicação entre os pares, sem a necessidade de transmitir ideias que refletem a realidade, mas sim uma verdade própria, criada a partir do ponto de vista do artista (PCN, 1997).

\footnotetext{
${ }^{9}$ Informações sobre o projeto estão disponíveis em:<_http://rived.mec.gov.br $>$. Acesso em: 02 de ago. 2009.

10 O Objeto de Aprendizagem "Calorímetro" tem como objetivo apresentar um modelo de bomba calorimétrica (calorímetro) a partir do desenvolvimento dos três conceitos básicos para a compreensão de seu funcionamento: energia, calor e temperatura. Sua versão original para o Projeto RIVED está disponível em: <http://data.dco.fc.unesp.br/ rived/2008/oa_calorimetro/>. Acesso em: 10 ago. 2009.
} 
O que distingue essencialmente a criação artística das outras modalidades de conhecimento humano é a qualidade de comunicação entre os seres humanos que a obra de arte propicia, por uma utilização particular de formas de linguagem. (PCN, 1997, p. 37)

Assim comunicação através da linguagem da arte tem uma forma peculiar tanto para o produtor quanto para o leitor pois concretiza uma multiplicidade de significados para ambas as partes que participam dessa experiência, "é um modo particular de utilização das possibilidades da linguagem, criando um tipo diferenciado de comunicação entre as pessoas" (PCN, 1997 p. 38), comunicação esta que pode vir carregada de afetividade de todos os tipos, de emoções a sentido poético ou subjetividade, considerando as múltiplas possibilidades de leitura e interpretação desta.

Nesta mesma linha de pensamento Ferraz e Fusari (1993) dizem que a obra só completa seu ciclo com a participação do leitor e seu relacionamento com ela e pela mensagem expressa pelo artista através das diversas linguagens artísticas, considerando como produtor de arte não apenas o artista profissional, mas qualquer outro indivíduo que queira utilizar-se desta forma de comunicação para expressar pensamentos e ideias de seu mundo e da sua cultura, integrando "artistas - obras - público - modos de comunicação" e integrando-os dentro do meio social (FERRAZ; FUSARI, 1993, p. 17).

Ferraz e Fusari sistematizam de forma clara os elementos primordiais que estruturam qualquer processo de arte, organizando uma cadeia de componentes que podem ser tão dependentes entre si quanto relacionarem-se (FERRAZ; FUSARI, 1993). Autores, produtos artísticos, comunicação e público somam os ingredientes que confirmam a essência da arte como uma das formas de linguagem mais remotas na construção dos processos de comunicação entre os seres humanos e que vêm ao encontro da construção contemporânea de linguagem em consonância com as tecnologias digitais.

A respeito da história da arte como instrumento de linguagem sabemos que se faz presente nas primeiras manifestações estéticas da existência humana através dos registros pictóricos primitivos que por muito tempo seriam a única forma de comunicação e linguagem entre os primeiros seres humanos.

Considerando os Parâmetros Curriculares Nacionais e a referência que faz ao ensino de arte, destacam-se quatro principais linguagens no desenvolvimento das propostas educacionais: Artes Visuais, Dança, Música e Teatro. Tratadas como conteúdos abrangentes, também reportam às especificidades e heterogeneidades de cada

RIAEE - Revista Ibero-Americana de Estudos em Educação, Araraquara, v.12, n.4, p.2273-2291, out./dez. 2017. 
uma, que deve contemplar desde os conceitos clássicos estabelecidos nos períodos da História da Arte aos da contemporaneidade em suas mais diversas formas de expressão e suporte, considerando a arte como área de conhecimento.

Voltando-se para a área das Artes Visuais, o documento pontua formas de expressão mais contemporâneas "[...] que resultam dos avanços tecnológicos e transformações estéticas a partir da modernidade (fotografia, artes gráficas, cinema, televisão, vídeo, computação, performance) [...]" (PCN, 1997 p. 61) bem como a possibilidade da combinação desses vários meios de expressão, na busca de criações poéticas que colaborem para que o aluno "passe por um conjunto amplo de experiências de aprender e criar, articulando percepção, imaginação, sensibilidade, conhecimento e produção artística pessoal e grupal” (PCN, 1997 p. 61). Ou seja, o documento trata das novas tecnologias como forma de expressão e considera os suportes contemporâneos como meios de materializar sentimentos e ideias que possam responder aos estímulos propostos em situações educacionais.

A este respeito, Barbosa pensa as ideias dos processos de produção em arte em consonância com a tecnologia e as possibilidades estéticas oriundas da hibridização dos códigos e linguagens operadas pela arte nos dias atuais (BARBOSA, 2008):

Vivemos a era "inter". Estamos vivendo um tempo em que a atenção está voltada para a internet, a interculturalidade, a interdisciplinaridade, e a integração das artes e dos meios como modos de produção e significação desafiadores de limites, fronteiras e territórios. (BARBOSA, 2008, p. 23)

Segundo a autora este formato contemporâneo favorece a interdisciplinaridade e a interação de diferentes competências, transcendendo limites e estabelecendo novos diálogos. São benefícios que entendemos serem urgentes já que os " $[\ldots]$ currículos engessados pelas especialidades já não correspondem às interconexões, interpenetrações e sincretismos gerados por valores culturais mais democráticos e pelas novas tecnologias" (BARBOSA, 2008 p. 24). Diante das possibilidades de articulação da arte com as novas mídias e suportes tecnológicos temos como fato o uso frequente dos aplicativos, jogos, redes sociais e outros meios por crianças e adolescentes, até mesmo com temáticas artísticas.

Confirmando o conceito de arte como linguagem e das possibilidades de integração desta com os suportes tecnológicos Campos (2008) afirma que historicamente as artes sempre mantiveram ligações entre si e atualmente os novos 
meios de produção artísticos vêm sobretudo das tecnologias digitais que mudou radicalmente os processos de produção dentro deste meio (CAMPOS, 2008):

A tal ponto ela foi importante que se pode falar em um antes e depois da chegada, globalizada e acessível, da tecnologia computadorizada, que, além de implicar uma nova linguagem, veio proporcionar aos artistas o manuseio de equipamentos antes somente possível em estúdios caros e inacessíveis à minoria. (CAMPOS, 2008, p. 186).

Atribuímos então a arte a característica da linguagem multidisciplinar que com os suportes tecnológicos, sendo estes digitais ou não, amplia o poder de comunicação da arte em direção a contemporaneidade e as interconexões que Barbosa (2008) pontua em suas reflexões, assim como coloca Campos (2008), ambos em concordância com as expectativas dos Parâmetros Curriculares Nacionais para o Ensino de Arte. São fundamentações que nos fortalecem na busca de um ensino com suportes atuais como o objeto de aprendizagem sugerido por esta proposta.

\section{Encaminhamentos para o uso de objeto de aprendizagem nas aulas de arte}

Considerando as questões chaves tratadas a respeito de objeto de aprendizagem, arte como forma de linguagem, multidisciplinariedade e suportes tecnológicos, alinhando estas questões aos conceitos metodológicos de ensino da arte defendidos pela arte educadora Ana Mae Barbosa e ainda observando as concepções freireano de educação, propomos a sistematização de alguns encaminhamentos para o uso de objetos de aprendizagem em uma sequência de trabalho para o Ensino Fundamental 1. De acordo com os Parâmetros Curriculares Nacionais para o Ensino de Arte (1997, p. 6162,) a linguagem das Artes Visuais pode abranger modalidades de suportes que vão além dos tradicionais, combinar saberes em favor da expressão do aluno auxiliando nos projetos educacionais, articular elementos que dão origem as imagens e promover no aluno possibilidades de criação com poéticas próprias, valorizando a pessoalidade em seus trabalhos.

\section{a) Encaminhamentos para a leitura visual em arte com o uso objetos de aprendizagem:}

O mesmo documento traz, no bloco de conteúdos de Artes Visuais, entre outros, os seguintes argumentos quanto a apreciação significativa quanto ao objetivo:

RIAEE - Revista Ibero-Americana de Estudos em Educação, Araraquara, v.12, n.4, p.2273-2291, out./dez. 2017. 
Contato sensível, reconhecimento, observação e experimentação de leitura das formas visuais em diversos meios de comunicação da imagem: fotografia, cartaz, televisão, vídeo, história em quadrinhos, telas de computador, publicações, publicidade, desenho industrial, desenho animado. (PCN, 1997, p. 64)

Considera-se importante que o aluno tenha acesso aos meios e suportes que vão além dos livros didáticos para a apreciação e leitura de obras de Arte. As possibilidades de acesso ao universo imagético devem ser tão amplas quanto as novas mídias e suportes tecnológicos puderem ofertar, incluindo-se a este grupo o uso de recursos como tabletes e smartfones já que o documento defende a inclusão de formas contemporâneas para o aprendizado significativo. No contexto atual de inserção dos suportes tecnológicos no cotidiano de todos os seguimentos, podem fazer a diferença nos processos de ensino/aprendizado considerando-se o perfil de aceitação desta ferramenta por parte de crianças e jovens inseridos no processo educacional atual.

Brandão (1987), ao descrever o método de alfabetização proposto por Paulo Freire, faz referência ao método e aos instrumentos: “O método aponta regras de fazer, mas em coisa alguma ele deve impor formas únicas, formas sobre como fazer. De uma situação para outra, de um tempo para outro, sempre é possível criar sobre o método, inovar instrumentos e procedimentos de trabalho" (Brandão, 1987, p.27). Sob estas perspectivas e fundamentação dialogando com o ensino de arte, especificamente a leitura da imagem, de qualquer natureza que esta seja, confirmamos a utilização de O.A. em concordância com o perfil dos aprendizes atuais respeitando o contexto tecnológico no qual estão inseridos, sem desprezar os recursos tradicionais já que os mesmos também são elencados pelos parâmetros para o ensino de arte.

\section{b) Encaminhamentos para a contextualização cultural e histórica em arte com uso de objetos de aprendizagem:}

$\mathrm{Na}$ mesma linha do raciocínio da leitura visual, os Parâmetros trazem argumentos importantes quanto à contextualização das artes visuais como produto cultural e histórico. Entre elas pontuamos os seguintes objetivos a serem atingidos:

Observação, estudo e compreensão de diferentes obras de artes visuais, artistas e movimentos artísticos produzidos em diversas culturas (regional, nacional e internacional) e em diferentes tempos da

RIAEE - Revista Ibero-Americana de Estudos em Educação, Araraquara, v.12, n.4, p.2273-2291, out./dez. 2017. 
história. Contato frequente, leitura e discussão de textos simples, imagens e informações orais sobre artistas, suas biografias e suas produções. (PCN 1997, p. 64-65)

Compreendemos que faz parte do processo de aprendizagem em Arte a contextualização das imagens, textos, poesias, vídeos, desenhos, objetos e todos os outros produtos artísticos que possam ser motivo de discussão em alguma proposta educacional. Rizzi (2002) corrobora com essa visão ao contextualizar os produtos culturais e históricos “[...] estamos operando no domínio da História da Arte e outras áreas de conhecimento necessárias para determinado programa de ensino.” (RIZZI, 2002, p.69). Segundo a autora esta prática favorece o estabelecimento de relações e a interdisciplinaridade, uma tarefa complexa que tende a tornasse mais acessível com o uso de O.A. e da internet (RIZZI, 2002).

Nos fundamentos teóricos de Paulo Freire, a contextualização da aprendizagem parte do universo do educando e das circunstâncias de sua vida através da prática do diálogo, do respeito entre os saberes de ambas as partes, caracterizando uma ação educativa voltada para a coletividade e que seja extremamente sensível ao significado daquilo que se aprende. Das bases teóricas postuladas por Freire também se justifica a questão da contextualização dos saberes em Arte. Para Gomes (2015), em trabalho a respeito dos Círculos de Cultura criados por Paulo Freire como parte do seu método de alfabetização, a aprendizagem pode ir além dos espaços da sala de aula, extrapolando os limites impostos por uma educação compartimentada (GOMES, 2015):

\begin{abstract}
A aprendizagem ocorre ao mesmo tempo e em todo o lugar, indo além da sala de aula e da dimensão unilateral, torna-se omnilateral e ubíqua, potencializando o trabalho conjunto de diversas áreas de conhecimento realizado por investigadores em outras plataformas além da presencial. (GOMES, 2015, p. 21)
\end{abstract}

Sob este olhar, o uso dos O.A. nas situações de aprendizagem e de contextualização em Arte podem suprir as necessidades de pesquisar, comparar, contrastar, explorar e ampliar o repertório dos educandos a respeito dos mais diversos objetos, imagens, textos, vídeos e outras formas de arte a que estejam expostos. A partir de O.A. conectados as redes de internet o educando pode voltar-se ao contato direto com as questões mais atualizadas dos produtos artísticos e culturais de forma plural e interdisciplinar.

RIAEE - Revista Ibero-Americana de Estudos em Educação, Araraquara, v.12, n.4, p.2273-2291, out./dez. 2017. 


\section{c) Encaminhamentos práticos para trabalho com objetos de aprendizagem no ensino de arte no ensino fundamental $1 \mathrm{com}$ a linguagem das artes visuais:}

Ao entendemos Arte como área de conhecimento com suas especificidades e conteúdos percebemos que se trata se um componente curricular capaz de se relacionar com as demais disciplinas do currículo escolar. A contextualização cultural faz parte dos objetivos deste documento que trata da necessidade do conhecimento e do respeito das mais diversas culturas. Entre as inúmeras possibilidades de abordagem em arte, elencamos, para esta pesquisa, a pluralidade cultural através do trabalho com produções dos povos indígenas brasileiros por entendermos que tratar-se de um conteúdo relevante e necessário ao público destinado, uma vez que a imagem das populações nativas brasileiras é tratada de modo simplificado e estereotipado tanto pela historiografia tradicional quanto por boa parte dos livros didáticos que reproduzem este conteúdo segundo Lima (1995, p.394).

A situação de aprendizagem está diretamente sustentada pela abordagem triangular e pelos conceitos pedagógicos freireanos, utilizando o conceito de objeto de aprendizagem para a prática pensada.

Tabela 1: Sequência didática para o uso de objetos de aprendizagem em aulas de arte

\begin{tabular}{|c|c|c|c|}
\hline Objetivo & Proposta & $\begin{array}{l}\text { Fundamentação } \\
\text { Metodológica }\end{array}$ & $\begin{array}{c}\text { Objetos de } \\
\text { Aprendizagem }\end{array}$ \\
\hline $\begin{array}{l}\text { 1. Contato sensível, } \\
\text { reconhecimento, } \\
\text { observação e } \\
\text { experimentação de } \\
\text { leitura das formas } \\
\text { visuais em diversos } \\
\text { meios de comunicação } \\
\text { da imagem: } \\
\text { fotografia, cartaz, } \\
\text { televisão, vídeo, } \\
\text { histórias em } \\
\text { quadrinhos, telas de } \\
\text { computador, } \\
\text { publicações, } \\
\text { publicidade, desenho } \\
\text { industrial, desenho } \\
\text { animado. (PCN, 1997, } \\
\text { p. 64) }\end{array}$ & $\begin{array}{l}\text { Tela 1: apresentação de } \\
\text { três retratos } \\
\text { representando as } \\
\text { diferentes etnias que } \\
\text { compõe o povo } \\
\text { brasileiro: } \\
\text { a) COSTA, Arthur } \\
\text { Timótheo. Autorretrato, } \\
\text { 1908. }{ }^{11} \\
\text { b) PORTINARI, } \\
\text { Cândido. Autorretrato, } \\
\text { 1957. }{ }^{12} \\
\text { c) SALGADO, } \\
\text { Sebastião. Jovem } \\
\text { Marubo, } 1998 .{ }^{13}\end{array}$ & $\begin{array}{l}\text { Ler obras de arte: Leitura } \\
\text { formal e interpretativa das } \\
\text { imagens - Crítica e } \\
\text { Estética, segundo Rizzi } \\
\text { (2002). } \\
\text { Pesquisa do universo } \\
\text { (Paulo Freire): } \\
\text { Diálogo entre educador- } \\
\text { educando, educando- } \\
\text { educando, educando- } \\
\text { imagens, segundo } \\
\text { Brandão (1986). }\end{array}$ & $\begin{array}{l}\text { Projetor de slides } \\
\text { conectado a um } \\
\text { computador } \\
\text { manuseado pelo } \\
\text { professor mediador da } \\
\text { discussão. }\end{array}$ \\
\hline
\end{tabular}

${ }^{11}$ Disponível em: < http://www.pinturasemtela.com.br/artur-timoteo-da-costa-pintor-e-decorador-negrobrasileiro/>. Acesso em: 12 set. 2016.

${ }^{12}$ Disponível em: <http://www.portinari.org.br/\#/acervo/obra/1>. Acesso em: 12 set 2016.

${ }^{13}$ Disponível em: <http://www.amazonasimages.com/travaux-portraits>. Acesso em: 12 set 2016. 
2. Identificação dos produtores em artes visuais como agentes sociais de diferentes épocas e culturas: aspectos das vidas e alguns produtos artísticos

-Contato frequente, leitura e discussão de textos simples, imagens e informações orais sobre artistas, suas biografias e suas produções (PCN, 1997, p. 65)
Tela 2: apresentação de telas individuais abrindo contexto histórico das obras com informações relevantes a compreensão das mesmas.

Tela 3: informativa sobre cultura indígena trazendo informações a respeito da pintura corporal e contrastando com a cultura urbana de tatuagens, maquiagens, piercing.

Tela 4: multidisciplinar com link das imagens com a linguagem da música dentro mesmo contexto identidade cultural através da obra: BUARQUE, Chico. Paratodos. 1993.

\section{Experimentação, expressão e comunicação por imagens: fotografia (PCN, 1997, p. 63)}

\section{Produção de selfies} através de câmeras digitais a partir das discussões ampliadas nas etapas anteriores.
Contextualizar: operar no domínio da História da

Arte e outras áreas do conhecimento necessárias para determinado programa de ensino, segundo Rizzi (2002)

Decodificação da descoberta (Paulo Freire): debates a fundo sobre as questões que as obras sugerem, segundo Brandão (1986)
Projetor de slides conectado a um computador manuseado pelo professor mediador da discussão.
Fazer Arte: ação do domínio da prática artística segundo Rizzi (2002) com a produção de autorretratos pelos educandos.
Câmera digital acoplada ao computador ou aparelho celular.

\section{Criação e construção de formas plásticas e visuais em espaços diversos (bidimensional e tridimensional). (PCN, 1997, p. 62)}

\section{A partir trabalho com as imagens/sons e do foco na cultura indígena, produção de interferências gráficas na imagem selfie produzida na etapa anterior pelos educandos.}

\section{Fazer Arte: \\ Transformação, interpretação e criação com base em um referencial, segundo Rizzi (2002) através da produção de interferências nas imagens estimulada pelos conceitos trabalhados nas etapas anteriores e de acordo com o repertório artístico de cada educando na intenção de criar uma máscara a partir do autorretrato.}

Apresentação da
produção com a leitura
formal/interpretativa,
partilha e reflexão.
para a correlação dos conceitos, processos e produto final (Pcn, p.100)

\section{Contextualizar: \\ estabelecimento de relações que permitam a interdisciplinaridade segundo Rizzi (2002) através da apresentação das produções finalizadas; Leitura das imagens como em fichas de cultura (Paulo Freire): rever criticamente os conceitos}

\section{Microcomputadores com software Paint da Microsoft Windows, sendo um computador por aluno para a criação de pintura digital sobre a foto.}

Projetor de slides conectado a um computador manuseado pelo professor mediador para apresentação das artes criadas pelos alunos e discussões dos resultados.

RIAEE - Revista Ibero-Americana de Estudos em Educação, Araraquara, v.12, n.4, p.2273-2291, out./dez. 2017. 
Fonte: elaborada pelos autores

\section{Considerações finais}

Os Parâmetros Curriculares Nacionais para o ensino de Arte citam, entre muitos apontamentos, o professor com o papel de nutrir "[...] seus alunos com informações e procedimentos sobre arte tanto quanto orientador e preservador do desenvolvimento do trabalho pessoal do aluno, oportunizando a criação própria ou grupal" (PCN ARTE, 1997, p.50). Os objetos de aprendizagem que surgem por meio das tecnologias digitais complementando o conhecimento e a exploração de imagens, sons, cores, vídeos enriquecem o conteúdo proposto pelo arte educador.

Para Audino e Nascimento, objetos de aprendizagem "surgem como um recurso capaz de potencializar a reestruturação de práticas pedagógicas, criando novas maneiras de refletir sobre o uso da comunicação, da informação e da interação" (AUDINO; NASCIMENTO, 2010, p.130). No processo de aprendizagem em arte, das reflexões e indagações formais e interpretativas que surgem no momento em que o aluno está diante de uma obra, passando pelo momento de contextualização onde são trazidos os determinantes históricos da obra e confrontados com a história pessoal do aluno e seu repertório, o uso de objetos de aprendizagem adequados podem trazer essa "potencialização" da prática pedagógica que Audino e Nascimento (2010) apontam.

Desenvolver a abordagem triangular sistematizada por Barbosa (2007) aos recursos digitais através dos objetos de aprendizagem pode significar a ampliação das possibilidades de uma pesquisa mais aprofundada da obra de arte e sua contextualização.

A arte, quando compreendida e trabalhada como área de conhecimento pelo arte educador, traz reflexões e desperta o aluno para uma compreensão ampla do universo não verbal, das imagens, dos sons e dos gestos e dando-lhe a oportunidade de comunicar-se e expressar-se com propriedade e domínio. Através da apreciação da obra de arte e de a compreensão do seu contexto histórico, assim como o fazer artístico do aluno também podem representar um momento mais completo e rico através das tecnologias digitais que, quando utilizadas de maneira apropriada, como apoio 
imagético e de pesquisa, podem contribuir valiosamente nos processos de construção de conhecimento em arte.

Espera-se com essa pesquisa contribuir na motivação de professores arte educadores no uso coerente e amplo dos recursos digitais para que seus alunos construam novas leituras e interpretações de produções artísticas propiciado pelo acréscimo de conteúdos midiáticos e imagéticos.

\section{REFERÊNCIAS}

AMÉRICO, M. TV Digital: propostas para desenvolvimento de conteúdos em animação para o ensino de ciências. 2010. 213 f. Tese (Doutorado em Educação para a Ciência) - Faculdade de Ciências, Universidade Estadual Paulista, Bauru, 2010.

AUDINO, D. F.; NASCIMENTO, R. S. Objetos de Aprendizagem: Diálogos entre Conceitos e uma Nova Proposição Aplicada à Educação. Revista Contemporânea de Educação, v. 5, n. 10, p. 128-148, 2010.

BARBOSA, A. M. Inquietações e mudanças no ensino da arte. 7.ed. São Paulo: Cortez, 2007. 208 p.

BERTOLETTI, A. Tecnologia digital no ensino da arte: perspectivas e desafios. In: Encontro do NatFap: Núcleo de Arte e Tecnologia da Faculdade de Artes do Paraná, 1., 2011, Curitiba. Anais: Artigo. Curitiba: Faculdade de Artes do Paraná, 2011. p. 14-23.

CAMPOS, C. Processos artístico-criativos na evolução tecnológica: música/poesia e outras artes. In: BARBOSA, A. M. T. B.; AMARAL, L. (Org.). Interterritorialidade: mídias, contextos e educação. São Paulo: Editora Senac, 2008.

DA SILVA, J. M. C.; BAVARESCO, N.; SILVEIRA, R. A. Projeto e desenvolvimento de um sistema multi-agentes para objetos inteligentes de aprendizagem baseado no padrão scorm. Revista Brasileira de Informática na Educação, Florianópolis, v. 16, n. 01, p. 19-27, 2008.

FERRAZ, M. H. C. de T.; FUSARI, M. F. de R. Metodologia do ensino de arte. São Paulo: Cortez, 1993.

GUTIERREZ, S. S. Distribuição de conteúdos e aprendizagem on-line. Educational content syndication and online learning. Renote: Revista novas tecnologias na educação. Rio Grande do Sul, v. 2, n. 2, p. 1-14, 2004.

IEEE Learning Technology Standards Committee (LTSC). Draft Standard for Learning Object Metadata (IEEE 1484.12.1-2002). Julho de 2002. Disponível em: $<$ https://biblio.educa.ch/sites/default/files/20130328/lom_1484_12_1_v1_final_draft_0. pdf>. Acesso em: 25 fev. 2017.

MARTINS, M. C. Teoria e prática do ensino da Arte. 1.ed. São Paulo: FTD, 2009.

RIAEE - Revista Ibero-Americana de Estudos em Educação, Araraquara, v.12, n.4, p.2273-2291, out./dez. 2017. 
GUTIERREZ, S. S. Distribuição de conteúdos e aprendizagem on-line. Educational content syndication and online learning. Renote: Revista novas tecnologias na educação. Rio Grande do Sul, v. 2, n. 2, p. 1-14, 2004.

NUNES, C. A. A. Objetos de Aprendizagem em Ação. Cadernos de Pesquisa Reflexões, São Paulo, v.1, n.6, 2004.

BRASIL. Secretaria de Educação Fundamental. Parâmetros curriculares nacionais: arte /Secretaria de Educação Fundamental. Brasília: MEC/SEF, v.6, 1997.

PIMENTEL, L. G. Fruir, contextualizar e experimentar como possível estratégia básica para investigação e possibilidade de diversidade no ensino de arte: o contemporâneo de vinte anos. In: BARBOSA, A. M. T. B.; DA CUNHA, F. P. (Orgs.). A abordagem triangular no ensino das artes e culturas visuais. São Paulo: Cortez, p. 211 228, 2010 .

PIMENTEL, L. G. Tecnologias contemporâneas e o ensino da arte. In: BARBOSA, A. M. T. B. Inquietações e mudanças no ensino da arte. São Paulo: Cortez, p. 113-122, 2002.

PILLAR, A. D. A educação do olhar no ensino das artes. In: BARBOSA, A. M. T. B. Inquietações e mudanças no ensino da arte. São Paulo: Cortez, p. 71-81, 2002.

PORTELLA, Adriana. Aprendizagem da arte e o museu virtual do projeto Portinari. In.: BARBOSA, A. M. T. B. Inquietações e mudanças no ensino da arte. São Paulo: Cortez, p.123-138, 2002.

RIZZI, M. C. de S. Caminhos metodológicos. In: BARBOSA, A. M. T. B. Inquietações e mudanças no ensino da arte. São Paulo: Cortez, p. 63-70, 2002.

SILVA, A. L; GRUPIONI D. B. (Orgs.). A temática indígena na escola. 1.ed. Novos subsídios para professores de $1^{\circ}$ e $2^{\circ}$ graus. Brasília: MEC/MARI/UNESCO, 1995.

TAROUCO, L. M. R; FABRE, M. C. JM; TAMUSIUNAS, F. R. Reusabilidade de objetos educacionais. Renote: Revista novas tecnologias na educação. Rio Grande do Sul, v. 1, n. 1, p 1-11, fev. 2003.

VIEIRA, C. E. M; NICOLEIT, E. R. Desenvolvimento de objeto de aprendizagem, baseado em especificações de normatização SCORM, para o caso de suporte à aprendizagem de funções. Renote: Revista novas tecnologias na educação. Rio Grande do Sul, v. 5, n. 1, p 1-10, 2007.

WILEY, D. A. Connecting learning objects to instructional design theory: A definition, a metaphor, and a taxonomy. In: D. A. Wiley (Ed.), The Instructional Use of Learning Objects: Online Version. Disponível em:

<http://reusability.org/read/chapters/wiley.doc>. Acesso em: 12 jun. 2016. 


\section{Como citar este artigo:}

AMÉRICO, Marcos. et al. Proposta para construção de objeto de aprendizagem como apoio ao ensino de arte. Revista Ibero-Americana de Estudos em Educação, Araraquara, v. 12, n. 4, p. 2273-2291, out./dez. 2017. Disponível em: <http://dx.doi.org/10.21723/riaee.v12.n4.out./dez.2017.10167>. E-ISSN: 1982-5587.

Submetido em: 28/07/2017

Revisões requeridas: 17/09/2017

Aceito em: 06/011/2017 